so it may be interesting to compare the sequence of these RNAs, in particular the wobble positions, with the sequence of the Physarum transcript. Differences between the RNAs may reflect selectional constraints placed on the Physarum transcript by primary or secondary structures involved in the editing. Of course, a serious search for editing information in the pre-edited Physarum RNA would be complicated. However, given the rapid rate of progress in our understanding of RNA editing, it seems probable that the necessity of undertaking such a search will soon become evident.

Brenda L. Bass is in the Department of Biochemistry, University of Utah, 50 North Medical Drive, Salt Lake City, Utah 84132. USA.

\title{
Putting the pieces together
}

\section{William L. Ellsworth}

WHEN it rocked the San Francisco Bay area on 17 October 1989, the Loma Prieta carthquake (of magnitude, $M_{\mathrm{w}}, 6.9$ ) was embraced as fulfilling a long-term forccast for the rupture of the San Andreas fault in the southern Santa Cruz mountains'. Now, after an additional year of digging into old geodetic data - and, quite literally, into the fault itself - a new picture is beginning to emerge of comparatively infrequent rupture of a secondary fault trace along this reach of the San Andreas. These developments sparked a lively debate about the significance of this event and the prospects for additional activity along this segment of the fault at a recent meeting of the American Geophysical Union*.

The Loma Pricta earthquake ruptured a 40-km-long segment of the San Andreas fault along the southernmost end of the great 1906 earthquake $\left(M_{\mathrm{w}}=7.7\right)$ rupture, and was the first significant event to strike along it in the past 83 years. Faulting in 1989 propagated upward along a dipping plane to intersect the San Andreas at about $10 \mathrm{~km}$ depth. Right oblique reverse faulting on this plane raised the southwest (Pacific Plate) side of the fault $1.1 \mathrm{~m}$ and translated it $1.6 \mathrm{~m}$ to the northwest, relative to the northeast (North American Plate) side (sec box).

The occurrence of an earthquake along this segment of the fault had been predicted by a number of workers during the previous decade, principally on the basis of the time it would take to recover the strain that had been released there in 1906:.

Early on, it was speculated that the actual earthquake was an unusual event, as the large proportion of vertical slip did not fit the conventional model of transform fault motion along the San Andreas fault: Repetition of this event at a rate needed to match the local plate velocity should build high mountains, not the modest southern Santa Cruz mountains which rise to only $1,100 \mathrm{~m}$.

Part of the mystery about the behaviour of this segment of the fault stems from

*American Geophysical Union Fall Meeting, San Francisco, 3-7 December 1990. uncertainties about its behaviour in the 1906 carthquake. Although surface faulting was clear clsewhere along the fault ${ }^{+}$, the reported effects in the southern Santa Cruz mountains were dominated by secondary ground failures, many now suspected of being a gravitationally driven response to the shaking, just as occurred in the 1989 event. Thus, we have little direct evidence of how plate motion is accommodated locally.

With surface faulting also absent in 1989, Paul Segall and Mike Lisowski turned to the analysis of geodetic deformations induced by each event. They found that the two earthquakes displaced the nearest mark, Loma Pricta peak, in different directions, thereby demonstrating that the two events are not simply scaled versions of a single, characteristic displacement. The horizontal displacement in 1906 was nearly parallel to the fault trace, whereas the 1989 earthquake clearly moved the mark towards the fault, as well as parallel to it.

This oblique motion is well understood in terms of the mechanism of the Loma Prieta earthquake. At a minimum, 1906 must have involved $2.5 \pm 0.4 \mathrm{~m}$ of slip parallel to the fault at shallow depth $(0-10$ $\mathrm{km}$ ), whereas little slip occurred above $4-5 \mathrm{~km}$ in 1989 . It is possible, however, that the 1989 fault could have moved in the same manner in 1906 as well, as its $0.1 \mathrm{~m}$ transverse displacement of Loma Prieta peak would be undetectable in the 1906 measurements.

Grant Marshall (US Geological Survey, Menlo Park) strengthened the case that something was unusual about the 1989 event when he presented the elevation changes determined by relevelling. $\mathrm{He}$ corroborated the speculations (ref. 6; G. Valensise, Instituto Nazionale di Geofisica, Rome; S. N. Ward, University of California, Santa Cruz) that Loma-Prieta-type events uplift the marine terraces along the Santa Cruz coastline. As Valensise noted, the terraces can be fully built by Loma Prieta events occurring once every 600 years, assuming no other displacements add to or subtract from the measured uplift. Valensise also reported on preliminary investigations of the tectonic uplift of the youngest marine rocks in the area, the 5-million-year-old Purisima Formation. His results suggest that uplift proceeded at a rate of $0.5 \mathrm{~mm} \mathrm{yr}^{-1}$ over the past 3 million years, also indicating the infrequent occurrence of Loma-Prietatype events.

If recurring Loma Prieta events account for only 10-20 per cent of the expected San Andreas motion, where is the rest of it? New trenching investigations in the southern Santa Cruz mountains by David Schwartz and co-workers (US Geological Survey, Menlo Park) have encountered probable 1906 surface faulting at one site. If palaeoseismic investigations planned for the spring prove successful, we stand to learn if the 1906 event completes the picture, or if other hidden faults lies within

\section{Transform faults and vertical tectonics}

TRANSFORM faults accommodate lateral translation between two rigid lithospheric plates without either convergence or divergence along the plate boundary. Strictly speaking, this is true only when the transform fault describes a small circle about the Euler pole of relative motion between the two plates. When a transform fault deviates from the small circle azimuth, parts of the colliding plates must be removed if the deviation places the boundary into compression. Conversely, a hole must be filled if the plates diverge along the canted transform fault. The rate of destruction or voidfilling is equal to the slip rate along the properly oriented transform multiplied both by the width of the step, as measured normal to the plate boundary, and by the depth of the fault.

Along most of its 1,200-km length, the San Andreas fault lies within a few degrees of small circles (see figure overleaf). But, there are important exceptions, such as the 'Big Bend', where the fault strike deviates in either a clockwise or anticlockwise manner, placing the plate boundary into extension or compression, respectively ${ }^{9}$. The step-over along the fault in the southern Santa Cruz mountains measures about $10 \mathrm{~km}$. Here, the excess crustal volume attempting to pass through the bend amounts to about $3,000 \mathrm{~km}^{3}$ per million years, and is locally balanced, at least approximately, by the 'hole' formed along the Calaveras fault, at the bifurcation of the single fault strand into the parallel Hayward and San Andreas faults. The reverse motion in the Loma Prieta earthquake removed about a century's worth of the excess crust by contributing to the construction of these young mountains. 